\title{
LA LEY DE RACIONALIZACIÓN Y SOSTENIBILIDAD DE LA ADMINISTRACIÓN LOCAL, LA SUPRESIÓN DE LA COMPETENCIA MUNICIPAL EN MATERIA DE EDUCACIÓN Y SUS CONSECUENCIAS PARA LOS CENTROS ASOCIADOS DE LA UNED
}

\author{
Jorge Fernández-Miranda Fernández-Miranda \\ Profesor contratado Doctor \\ Acreditado a Profesor Titular por la ANECA \\ Departamento de Derecho Administrativo \\ Facultad de Derecho de la \\ Universidad Complutense de Madrid \\ jorgefm@der.ucm.es
}

\begin{abstract}
RESUMEN
El presente trabajo tiene por finalidad el estudio de las consecuencias de la Ley 27/2013, de 27 de diciembre, de Racionalización y Sostenibilidad de la Administración, en atención a la supresión de la competencia en materia de educación y sus consecuencias sobre el servicio que prestan los Centros Asociados de la UNED. En este sentido se hace necesario atender al significado y alcance del régimen transitorio aprobado por el legislador, a las nuevas exigencias establecidas para los consorcios, la articulación de la competencia objeto de estudio como una competencia delegada y los términos en los que la delegación debe producirse, el plazo y su contenido.

Palabras clave: UNED, competencias locales, educación.
\end{abstract}

\section{ABSTRACT}

The current piece of work has the purpose to study the consequences of the 27 December 27/2013 Law for the Rationalization and Sustainability of the Local Government, complying with the loss of competence regarding education and its consequences on the services offered by the UNED (Spanish National University of Distance Education) affiliated centers. In this vein, we need to consider the meaning and extent of the temporary regime passed by the ruler, the new demands established for committees, the consideration of the competence case of study as a delegated competence as well as the terms, deadline and content in which the delegation should take place.

Keywords: UNED (Spanish National University of Distance Education), local competences, education. 


\section{ZUSAMMENFASSUNG}

Die vorliegende Arbeit hat zum Ziel, die Auswirkungen des Spanischen Gesetzes 27/2013 vom 27. Dezember, zur Rationalisierung und zur Nachbaltigkeit der Kommunalen Verwaltung zu analysieren. Hierbei wird die Aufbebung der kommunalen Zuständigkeit auf dem Gebiet der Bildung sowie deren Auswirkungen auf die Zentren, die an die UNED angegliedert sind, untersucht. In diesem Sinne ist es zunächst nötig, die Bedeutung und die Reichweite der Übergangsregelung zu erfassen, die vom Gesetzgeber verabschiedet wurde und die Anforderungen, die an die Stadträte gerichtet sind, beinhaltet. Danach wird die Einteilung und die Delegation der Zuständigkeit untersucht, ebenso die Umstände, unter denen die Delegierung erfolgen soll, ibre Frist und ibr Inbalt.

Schlüsselwörter: UNED (Spanische Fernuniversität), lokale Zuständigkeiten, Bildung.

SUMARIO: I. INTRODUCCIÓN.-II. LOS CENTROS ASOCIADOS DE LA UNED. UNA REALIDAD IMPLANTADA.-III. LA UNIVERSIDAD NACIONAL DE EDUCACIÓN A DISTANCIA. NATURALEZA Y RÉGIMEN JURÍDICO. SU VINCULACIÓN AL ESTADO Y SUS CONSECUENCIAS EN RELACIÓN AL REPARTO DE COMPETENCIAS EN MATERIA EDUCATIVA.-IV. EL RÉGIMEN TRANSITORIO DERIVADO DE LA DISPOSICIÓN ADICIONAL NOVENA LRSAL. SUS INCONGRUENCIAS.-V. LA «COOPERACIÓN CON LA ADMINISTRACIÓN EDUCATIVA A TRAVÉS DE LOS CENTROS ASOCIADOS DE LA UNED» COMO UNA COMPETENCIA DELEGADA EX ART. 27.3.o) LBRL.-VI. LAS CONSECUENCIAS DE LA LRSAL SOBRE EL RÉGIMEN JURÍDICO DE LOS CONSORCIOS Y SUS IMPLICACIONES PARA LOS CENTROS ASOCIADOS DE LA UNED.-VII. CONCLUSIONES.

\section{INTRODUCCIÓN}

La Ley de Racionalización y Sostenibilidad de la Administración Local - Ley 27/2013, de 27 de diciembre- ${ }^{1}$, en la que se contempla la supresión de la competencia municipal en materia educativa, supone un importante problema para la Universidad Nacional de Educación a Distancia respecto al desarrollo de la actividad educativa que desempeña a través de los Centros Asociados.

El presente trabajo pretende realizar un análisis de las modificaciones introducidas por la $\mathrm{LRSAL}^{2}$ a los efectos de determinar la vía más adecuada

\footnotetext{
${ }^{1}$ BOE, núm. 312, de 30 de diciembre de 2013 (en adelante LRSAL).

2 Muchos son ya los trabajos realizados sobre las implicaciones derivadas de la LRSAL. Véanse J. A. SANTAMARía PASTOR (dir.), La reforma de 2013 del régimen local español,
} 
para dar una respuesta que, sin contradecir el espíritu de la reforma, permita mantener un servicio de referencia tanto nacional como internacional. Se trata de evitar que la regulación transitoria establecida por la norma, sumado a la inactividad en la que está inmerso el ejecutivo estatal, termine por imposibilitar o menoscabar la subsistencia de los Centros Asociados de la Universidad Nacional de Educación a Distancia ${ }^{3}$. Todo ello desde una perspectiva fundamentalmente jurídica, pero sin olvidar la realidad económica, verdadera razón de ser de la presente reforma. Asimismo, destacando que el servicio público objeto de nuestro estudio es de naturaleza fundamentalmente educativa, no se puede comprender sin la necesaria atención a su indiscutible repercusión social y cultural. De tal forma que no sólo está en juego el sostenimiento del modelo, sino lograr que se respete la propia esencia y razón de ser de la UNED en el sistema educativo español, conscientes en todo momento de que es ya una realidad respetuosa — paradójicamente- con los principios de eficacia y eficiencia que tanto propugna la LRSAL.

Finalmente debe destacarse que el derecho tiene una capacidad limitada para conformar la realidad; razón por la cual si dicha realidad existe y ha sido —no sin dificultades - propiciada por el ordenamiento, ningún sentido tiene que más de cuarenta años después sea una regulación sectorial la que suponga un ataque directo al modelo de Centros Asociados de la UNED, máxime cuando el mismo funciona y respeta los parámetros de calidad, eficacia y eficiencia.

\section{LOS CENTROS ASOCIADOS DE LA UNED. UNA REALIDAD IMPLANTADA}

Diagnosticado el problema (supresión de la competencia municipal en educación) y conscientes de sus resultados (desaparición de los Centros Asociados de la UNED en su concepción actual, en la que el municipio es pieza clave del modelo), debemos centrar nuestra atención — antes de analizar la reforma y de proponer una solución específica- en la importante labor que desempeña la UNED ${ }^{4}$ no sólo desde un punto de vista forma-

Madrid-Barcelona, Fundación Democracia y Gobierno Local, 2014, y T. QuintAnA LóPEZ (dir.), La reforma del régimen local, Valencia, Tirant lo Blanch. 2014. Incluso previos a la reforma véase L. Cosculluela Montaner y L. Medina Alcoz (dirs.), Crisis económica y reforma del régimen local, Madrid, Civitas Thomson Reuters, 2012.

3 En adelante UNED.

${ }^{4}$ Destacando al respecto que la UNED, a través de los Centros Asociados, es ya una 
tivo-educativo — toda vez que es una universidad—, sino desde una perspectiva social y cultural, ya que se ha convertido en una realidad integradora y dinamizadora de la sociedad en las zonas en las que se ha implantado.

En este sentido es importante destacar la importancia que en dicho modelo ha tenido la participación municipal (y provincial) otorgándole un significado único desde el instante en el que permite a dicho ámbito, el más cercano al ciudadano, participar activamente. Como ejemplo notorio podemos hacer referencia a la propia nomenclatura de los Centros Asociados de la UNED, cuya denominación es Centro Asociado «de» y no «en». Con ello se ponen de manifiesto dos cosas al menos:

a) En primer lugar, que los Centros Asociados así concebidos no son meras delegaciones administrativas de la sede central, sino entidades educativas y sociales propias y específicas de los territorios donde se encuentran ubicadas, máxima expresión de la interacción existente y de la posibilidad de que el ámbito local pueda participar en los órganos de gobierno que se constituyen a los efectos de su oportuna gestión. Es decir, los Centros Asociados son percibidos y sentidos como algo propio de las localidades y comarcas donde se hayan implantado y no como meros órganos de gestión de una realidad que les es lejana y ajena.

b) En segundo lugar, porque su origen va de abajo hacia arriba, ocupándose la UNED de dar forma y contenido a las inquietudes educativas y culturales que surgen a nivel local. La historia de la creación de los centros así lo demuestra (iniciativas populares y políticas surgidas en el seno de la sociedad) ${ }^{5}$.

Sólo así puede entenderse el verdadero significado de los Centros Asociados y su valor añadido, debiendo buscar fórmulas que permitan mantener la participación del poder local en la gestión y administración de tales centros evitando la ruptura de los canales existentes hasta ahora que no sólo benefician a los Centros Asociados de la UNED, sino que le otorgan

realidad construida y asentada organizativa, económica y socialmente. Que en la actualidad atiende a más de 200.000 alumnos diseminados por toda la geografía nacional, numerosos Estados de la UE y de Hispanoamérica, sin olvidar los centros en USA, Japón y Guinea ecuatorial, y la singularidad de los centros penitenciarios y la atención a más de 5.000 alumnos discapacitados.

5 Se trata, por tanto, de una realidad que debe ser entendida en origen, eminentemente local-municipal, y proyectada —en cuanto al alumnado- sobre un ámbito supramunicipal. Cobrando al respecto importancia el nivel provincial, cuya participación en el modelo es indiscutible. 
un significado y un valor único. De tal manera que, siendo cierto que la UNED es consecuencia lógica del esfuerzo colectivo que la hizo y la hace posible, no es menos cierto el papel que al respecto ha venido a corresponder a los municipios — sin desmerecer en absoluto el realizado por otras instancias públicas y privadas-, dando un sentido y un significado propio y específico a cada uno de los Centros Asociados. Sólo así se comprende la magnitud e importancia de los Centros Asociados de la UNED, su significado y alcance en términos educativos, sociales y culturales.

Asimismo debemos destacar, por estar en consonancia con la propia reforma que se deriva de la LRSAL, que el servicio que presta la UNED se caracteriza por su eficacia y eficiencia ${ }^{6}$, siendo la inversión que se destina para mantener el servicio a través de los Centros Asociados muy inferior a la ratio existente para cualquier otra universidad pública española. En este punto estamos hablando de una inversión que viene siendo aportada por el sector público: a nivel local por los municipios y provincias, a nivel regional por las respectivas Comunidades Autónomas y a nivel de la Administración educativa por la propia UNED, y por el sector privado (fundamentalmente las Cajas de Ahorros, si bien su participación ha decaído enormemente a consecuencia de la crisis económica).

De tal forma que el servicio que presta la UNED debe ser entendido como un servicio público que se da en términos de estricta eficiencia económica, a lo que debemos sumar su importante trascendencia desde una perspectiva educativa, pero también cultural y social.

Dicho lo cual, y al margen de la competencia que todavía ostentan los municipios en materia de cultura, la supresión de la competencia en materia de educación supone un grave problema para la subsistencia de los Centros Asociados, dependientes en cualquier caso del nivel municipal.

Varias son las cuestiones que deben ser objeto de reflexión a los efectos de poder resolver adecuadamente los problemas derivados de la LRSAL. En primer lugar, debe quedar claro quién es el legislador y administración territorial (Estado/Comunidades Autónomas) competente. Para lo cual será imprescindible atender a la naturaleza y régimen jurídico de la UNED. En segundo lugar, será necesario atender al régimen transitorio articulado por la LRSAL, su significado y alcance. En este punto estudiaremos el art. 7.4 LBRL en su redacción dada por la LRSAL, su razón de ser y su verdadero alcance. Finalmente deberemos responder a la solución que

\footnotetext{
${ }^{6} \mathrm{Al}$ respecto véase La contribución económica y social de la UNED, elaborado por el Instituto Valenciano de Investigaciones Económicas (IVIE).
} 
finalmente se deriva de la LRSAL y que no es otra que la articulación de una competencia (educativa en relación a la cooperación con los Centros Asociados de la UNED) que pasa de ser propia a delegada, debiendo analizar sus consecuencias desde la perspectiva de la autoridad competente para ejercer dicha delegación, su régimen jurídico y su contenido en atención a las propias singularidades de la competencia a delegar. Finalmente, pero directamente vinculado con el ejercicio de la competencia de referencia en atención a la perspectiva organizativa, debemos destacar las consecuencias de la LRSAL y de las posteriores leyes aprobadas (Ley 15/2014, de 16 de septiembre, sobre racionalización del sector público y otras medidas de reforma administrativa) en el régimen jurídico de los consorcios. Cuestiones todas ellas necesarias para hacernos una idea correcta de las implicaciones normativas que la LRSAL tiene en la implantación, sostenimiento y funcionamiento de los Centros Asociados de la UNED.

\section{LA UNIVERSIDAD NACIONAL DE EDUCACIÓN A DISTANCIA. NATURALEZA Y RÉGIMEN JURÍDICO. SU VINCULACIÓN AL ESTADO Y SUS CONSECUENCIAS EN RELACIÓN AL REPARTO DE COMPETENCIAS EN MATERIA EDUCATIVA}

Expuesta la importancia —educativa, social y cultural— de la función desempeñada por la UNED a través de los Centros Asociados, debemos comenzar analizando quién es el legislador, así como la Administración (estatal o autonómica) a quien corresponde ejercer las competencias atribuidas por la LOU.

Tratándose de una cuestión aparentemente sencilla, no lo es tanto a la vista de los acontecimientos. En este sentido debe quedar claro que la competencia reside en el legislador estatal y en el gobierno y Administración General del Estado, como así se desprende de la disposición adicional primera de la LOU, en atención a la cual se establece que: «Las Cortes Generales y el gobierno ejercerán las competencias que la presente ley atribuye, respectivamente, a la Asamblea Legislativa y al Consejo de Gobierno de las Comunidades Autónomas en cuanto se refiere a las universidades creadas o reconocidas por Ley de las Cortes Generales, de acuerdo con lo establecido en el art. 4, y en atención a las especiales características y ámbito de sus actividades, a la Universidad Nacional de Educación a Distancia y a la Universidad Internacional Menéndez Pelayo». 
Consecuentemente debe quedar diáfano, desde este preciso instante, la vinculación de la UNED al Estado ${ }^{7}$, debiendo cumplir con las obligaciones derivadas de la LOU tanto el legislador como el ejecutivo estatal. Cuestión ésta que exige dos observaciones:

Una primera relacionada con la necesidad de que el gobierno aprehenda la posición que le corresponde ejercer respecto a la UNED. Pues el análisis de la evolución de la misma ${ }^{8}$, desde el mismo momento de su creación, es que el Estado mantiene una cierta pasividad, en nada beneficiosa para su normal funcionamiento. Siempre respondiendo pero con la sensación de que no se acaba de asumir el importante papel que la LOU atribuye al legislador y al gobierno estatales respecto a la UNED.

En segundo lugar, porque la indiscutible competencia estatal sobre la materia arroja ciertas dudas sobre alguna interpretación de las distintas leyes autonómicas de adaptación a la LRSAL ${ }^{9}$, en las que, evidentemente, se pronuncian sobre la materia educativa, pero sin consecuencias sobre la cuestión que nos ocupa, pues debe entenderse que el legislador competente será el estatal, no siendo las leyes autonómicas apropiadas para la regulación de una cuestión sobre la que no ostentan - a la luz de la propia LOU- competencia material alguna. Cuestión ésta que se desprende del análisis de las distintas leyes de referencia, en las que se menciona la competencia educativa en términos generales sin hacer referencia a la

7 Si se quiere profundizar véase D. CÁmara del Portillo, «Régimen jurídico de la Universidad Nacional de Educación a Distancia», en J. González GARCía (dir.), Comentarios a la Ley Orgánica de Universidades, Madrid, Civitas, 2009, pp. 1237 y ss.

${ }^{8}$ E. Pérez Vera y F. Fernández-Miranda Alonso, «La consolidación del sistema. Los Estatutos de la UNED», en Veinticinco años de la UNED, Madrid, UNED, 1979.

9 Al respecto véanse Decreto-ley 2/2014, de 21 de noviembre, de medidas urgentes para la aplicación en las Islas Baleares de la Ley 27/2013, de 27 de diciembre, de racionalización y sostenibilidad de la Administración local (BOIB, de 22 de noviembre); Ley 6/2014, de 13 de octubre, de medidas urgentes para la garantía y continuidad de los servicios públicos en la Comunidad Autónoma de la Región de Murcia, derivada de la entrada en vigor de la Ley 27/2013, de 27 de diciembre, de racionalización y sostenibilidad de la Administración local (BORM, de 17 de octubre); Decreto-ley 4/2014, de 22 de julio, por el que se establecen medidas urgentes para adaptar los convenios, los acuerdos y los instrumentos de cooperación suscritos entre la Administración de la Generalidad y los entes locales de Cataluña a la disposición adicional novena de la Ley 27/2013, de 27 de diciembre, de racionalización y sostenibilidad de la Administración local (DOGC, de 24 de julio); Decreto-ley 1/2014, de 27 de marzo, de medidas urgentes para la garantía y continuidad de los servicios públicos en Castilla y León, derivado de la entrada en vigor de la Ley 27/2013, de 27 de diciembre, de racionalización y sostenibilidad de la Administración local (BOCL, de 31 de marzo), y Ley $1 / 2014$, de 25 de julio, de adaptación del régimen local de la Comunidad de Madrid a la Ley 27/2013, de 27 de diciembre, de racionalización y sostenibilidad de la Administración local (BOCM, de 29 de julio de 2014), entre otras. 
UNED, lo que no significa que deba quedar incluida, por cuanto la nueva regulación derivada de la LRSAL hace ya mención expresa al servicio de la UNED y porque el legislador y administración competente -antes y ahora- es el Estado. No pudiendo las Comunidades Autónomas pronunciarse al respecto.

\section{EL RÉGIMEN TRANSITORIO DERIVADO DE LA DISPOSICIÓN ADICIONAL NOVENA LRSAL. SUS INCONGRUENCIAS}

Con anterioridad a la reforma articulada por la LRSAL y en atención al apartado segundo de la disposición adicional segunda de la $\mathrm{LOU}^{10} \mathrm{y}$, a raíz de la misma, del art. 126 de los Estatutos de la UNED ${ }^{11}$, podría entenderse la existencia de competencia municipal propia ex arts. 25.2.m) y 25.2.n) LBRL sobre la materia que ahora nos ocupa. Ahora bien, tras la reforma por la LRSAL observamos que se mantiene la competencia en materia de cultura [apartado $m$ )] del mencionado precepto en lo que se refiere ahora a «promoción de la cultura y equipamientos culturales», desapareciendo, sin embargo, el apartado $n$ ) relativo a «participar en la programación de la enseñanza y cooperar con la Administración educativa en la creación, construcción y sostenimiento de los centros docentes públicos e intervenir en sus órganos de gestión». En este sentido debemos acudir al art. 27 LBRL — competencias delegadas-, en su redacción dada por la LRSAL, y en cuyo apartado $o$ ) se establece la «cooperación con la Administración

${ }^{10} \mathrm{La}$ DA 2. ${ }^{\text {a }}$ LOU, «De la Universidad Nacional de Educación a Distancia» (Ley 6/2001, de 21 de diciembre), establece en sus apartados primero y segundo lo siguiente: «1. La Universidad Nacional de Educación a Distancia impartirá enseñanza universitaria a distancia en todo el territorio nacional. 2. En atención a sus especiales características, el gobierno establecerá, sin perjuicio de los principios recogidos en esta Ley, una regulación específica de la Universidad Nacional de Educación a Distancia que tendrá en cuenta, en todo caso, el régimen de sus Centros Asociados y de convenios con las Comunidades Autónomas y otras entidades públicas y privadas, las específicas obligaciones docentes de su profesorado, así como el régimen de los tutores».

${ }^{11}$ Real Decreto 1239/2011, de 8 de septiembre. El art. 126 de los Estatutos de la UNED establece que «los Centros Asociados son creados a iniciativa de la las Comunidades Autónomas, los Entes Locales u otras entidades públicas o privadas mediante convenio que garantizará el correcto funcionamiento del centro, su estabilidad y adecuada financiación, y que regulará la constitución de un consorcio, fundación u otra persona jurídica, así como del patronato, junta rectora u órgano colegiado de gobierno equivalente». 
educativa a través de los Centros Asociados de la Universidad Nacional de Educación a Distancia».

Es aquí donde reside el problema fundamental, centrado en la supresión de la competencia municipal en materia educativa, que permitía a los municipios firmar convenios en virtud de los cuales se constituía, mantenía y garantizaba el correcto funcionamiento de los Centros Asociados.

Partiendo de dicha modificación, no carente de múltiples problemas que más adelante analizaremos, el legislador introduce en la disposición adicional novena de la LRSAL titulada «Convenios sobre ejercicio de competencias y servicios municipales» un apartado segundo en el que recoge lo siguiente:

«La adaptación a las previsiones de esta Ley de los instrumentos de cooperación suscritos por las entidades locales para el funcionamiento de Centros Asociados de la Universidad Nacional de Educación a Distancia deberá realizarse en el plazo de tres años desde su entrada en vigor. Durante el plazo de adaptación de los instrumentos de cooperación, la financiación de las Administraciones locales a los Centros Asociados no se extenderá a los servicios académicos que se presten a los alumnos matriculados con posterioridad a la entrada en vigor de esta Ley».

Su origen y razón de ser la encontramos — como ya hemos advertido- en la supresión de la competencia municipal propia en materia educativa, lo que nos obliga a realizar un análisis de su contenido debiendo distinguir lo jurídico de lo económico. Asimismo, en relación a la financiación habrá que diferenciar el significado de la referencia a los gastos académicos, así como a la limitación temporal impuesta. Finalmente, habrá que apelar a la necesaria «prudencia jurídica» para defender la continuidad del servicio público como consecuencia de la inconsistencia de ciertas interpretaciones por su contradicción con el sostenimiento de los Centros Asociados desde un punto de vista jurídico, analizando las posibles consecuencias del régimen articulado.

En relación a lo primero (cobertura jurídica de los convenios firmados con anterioridad a la aprobación de la LRSAL) llama la atención que se otorga un régimen transitorio de tres años, a lo largo de los cuales se adaptarán los instrumentos de cooperación suscritos por las entidades locales para el funcionamiento de los Centros Asociados. Una cobertura jurídica a los convenios de referencia muy generosa que contrasta con la previsión realizada para el resto de convenios y que, de conformidad con el aparta- 
do primero de la disposición adicional novena, se darán por extinguidos si no se adecúan a 31 de diciembre de 2014.

Previsión ésta que afecta, sin embargo, a la financiación de las Administraciones locales a los Centros Asociados, por cuanto la misma «no se extenderá a los servicios académicos que se presten a los alumnos matriculados con posterioridad a la entrada en vigor de esta Ley». Esta previsión resulta a un mismo tiempo perturbadora, contradictoria e ininteligible, poniendo en duda la coherencia normativa y la necesaria y exigible seguridad jurídica. Y ello por las siguientes razones:

- Primero, porque no comulga con la cobertura jurídica otorgada a los convenios vigentes (tres años).

- Segundo, porque cuestiona el alcance de la misma. Es decir, poco sentido tiene que respetes la validez (jurídica) de un convenio cuando a continuación lo vacías de contenido (económico) en cuanto a uno de sus elementos esenciales, como es la financiación del propio servicio. ¿Cómo es posible que el legislador permita la continuidad durante tres años del servicio que presta la UNED a través de los Centros Asociados y que acto seguido impida su oportuna financiación? ¿No es ésa una de las razones fundamentales por las que se celebra el convenio: dar cobertura jurídica que permita su implantación y posterior prestación, permitiendo a su vez colaborar en su efectivo sostenimiento?

- Tercero, porque su redacción es expresiva de que se quiere introducir una limitación —en sí misma contradictoria en los términos señalados- pero que además resulta incomprensible en su contenido. Debemos preguntarnos a qué se está refiriendo el legislador al señalar que «la financiación de las Administraciones locales a los Centros Asociados no se extenderá a los servicios académicos que se presten a los alumnos matriculados con posterioridad a la entrada en vigor de esta Ley». La primera duda está relacionada con el hecho de que el problema se circunscribe a los servicios académicos, afectando, por tanto, al pago de las tutorías que se imparten en dichos centros, pero no así —al menos aparentemente- a otros gastos sumamente importantes como la cesión de espacios. Aspecto éste curioso, por cuanto la vinculación entre el espacio y el servicio académico es directa. La segunda duda está relacionada con la referencia a los alumnos matriculados con posterioridad a la entrada en vigor de esta Ley. Más allá de las consideraciones en cuanto 
al plazo, toda vez que estamos hablando de un servicio vinculado a un cómputo ${ }^{12}$ que no se corresponde con el año natural, sino con el curso académico, debemos advertir que dicho concepto acepta innumerables interpretaciones, todas ellas encuadrables dentro del marco legal. Debemos, por tanto, centrar nuestra atención en el alcance y significado de la referencia «alumnos matriculados». Al respecto se puede llegar a entender:

a) Desde una perspectiva material, el legislador deja a salvo a los antiguos alumnos. En este punto si el concepto de antiguos alumnos (concepto que habría que concretar) fuera válido a un solo antiguo alumno que haya en el aula (o que simplemente pueda haber), supondrá el pago del servicio académico, pues el mismo no diferencia en atención al número de alumnos que reciben la prestación de la tutoría (servicio académico).

b) Desde una perspectiva formal, el concepto resulta, sin embargo, menos amplio, ya que todo alumno es formalmente hablando, y para cada curso académico, un nuevo alumno matriculado. Interpretación ésta más restrictiva en cuanto al alcance real de la cobertura económica respecto a los servicios académicos.

c) Por otro lado cabe la posibilidad de que la referencia que ahora analizamos - alumnos matriculados-vaya referida y vinculada al propio servicio, de tal manera que lo que se está impidiendo es incrementar el techo de gasto. Es decir, no se admitirán nuevas titulaciones, sino sólo las ya impartidas.

Extremo este último que parece ser el más razonable por cuanto es más respetuoso con la cobertura jurídica que se dispensa a los convenios (de tres años), con la necesaria continuidad del servicio público y con la estabilidad presupuestaria que persigue la reforma, evitando vaciar de contenido el inciso final que ahora comentamos, pues, de lo contrario, habría bastado con el inciso primero, sin más contemplaciones.

Sea como fuere, el problema radica en el margen interpretativo que deja le ley y que dificulta el cumplimiento de la norma, siendo necesaria una clarificación por parte del Estado, quien sin ninguna duda es la Administración competente para — dentro de la legalidad— dar una res-

${ }_{12}$ Es decir, en la interpretación más rigurosa queda a salvo —en nuestra opiniónel curso académico 2013-2014 y su correspondiente financiación en cuanto a los servicios académicos. 
puesta que permita tener a los municipios (y provincias) la necesaria seguridad jurídica.

En este sentido debemos ser conscientes de que la consecuencia de llegar a la interpretación más rigurosa sería el necesario cierre de los Centros Asociados, y todo ello con origen en la inactividad mostrada por la AGE, inoperante en todo momento sobre el problema en cuestión ${ }^{13}$. Por suerte, la prudencia jurídica, la necesaria continuidad del servicio público, el indudable cumplimiento de los principios postulados por la reforma (eficacia y eficiencia) y la voluntad política del nivel municipal (y provincial) de seguir apostando por un servicio con un indiscutible valor académico, social y cultural ha garantizado, al menos de momento, su sostenimiento.

Ahora bien, debemos insistir en la temporalidad de la medida y en la necesidad de buscar soluciones en tanto en cuanto el gobierno no proceda a la efectiva delegación de la competencia.

En este punto, y como posible solución al problema que nos ocupa, está el reciente art. 7.4 LBRL, debiendo analizar el verdadero alcance del nuevo mecanismo articulado por la LRSAL relacionado con aquellas competencias que ni son propias ni delegadas, advirtiendo desde ya del problema derivado de que nos encontramos ante una competencia delegada, lo que limitaría de entrada su puesta en práctica. Ahora bien, aun siendo este razonamiento cierto en lo formal, no lo es en lo material, puesto que a día de hoy no se ha producido la delegación efectiva de la competencia, produciéndose la paradójica situación de que los municipios siguen pudiendo ejercer la competencia en los términos previstos en los convenios firmados con anterioridad a la LRSAL pero sin poder hacer efectivo el pago para los compromisos relacionados con los servicios académicos strictu sensu. Por tanto, se trataría de buscar una solución no para poder ejercer la competencia — durante el período transitorio-, sino para poder presupuestar y hacer efectivo el pago relacionado con los servicios académicos.

Dicho lo cual el art. 7.4 LBRL en su redacción dada por la LRSAL establece que: «Las entidades locales sólo podrán ejercer competencias distintas de las propias y de las atribuidas por delegación cuando no se ponga en riesgo la sostenibilidad financiera del conjunto de la Hacienda municipal, de acuerdo con los requerimientos de la legislación de estabilidad pre-

13 Primero, al no emitir una nota interpretativa del verdadero alcance del inciso final de la DA 9. ${ }^{a}$ LRSAL. Segundo, porque el problema se resolvería de inmediato mediante la efectiva delegación de la competencia derivada del art. 27.3.o) consistente en «cooperación con la Administración educativa a través de los Centros Asociados de la Universidad Nacional de Educación a Distancia». 
supuestaria y sostenibilidad financiera, y no se incurra en un supuesto de ejecución simultánea del mismo servicio público con otra Administración Pública. A estos efectos, serán necesarios y vinculantes los informes previos de la Administración competente por razón de la materia, en los que se señale la inexistencia de duplicidades, y de la Administración que tenga atribuida la tutela financiera sobre la sostenibilidad financiera de las nuevas competencias. En todo caso, el ejercicio de estas competencias deberá realizarse en los términos previstos en la legislación del Estado y de las Comunidades Autónomas».

Ahora bien, esta fórmula no ha sido empleada, por cuanto la interpretación dada a la disposición adicional novena ha sido la más generosa dentro de la legalidad en los términos ya explicados con anterioridad. Sea como fuere, no se puede desconocer que, siendo el requisito previo la necesaria estabilidad presupuestaria, ningún municipio ha acudido a esta fórmula por encerrar un mecanismo de control al que nadie voluntariamente quiere ofrecerse. Todo ello sin mencionar el sinsentido de una solución que, en el fondo, lo único que pretendería es salvar la incongruencia del régimen transitorio derivado de la LRSAL.

\section{LA «COOPERACIÓN CON LA ADMINISTRACIÓN EDUCATIVA A TRAVÉS DE LOS CENTROS ASOCIADOS DE LA UNED» COMO UNA COMPETENCIA DELEGADA EX ART. 27.3.O) LBRL}

Siendo evidentes las dudas y problemas derivados del régimen transitorio establecido por el legislador, debemos ser conscientes de que todo estaría resuelto si el Estado hubiera decidido hacer efectiva la delegación de la competencia para la cooperación de la Administración educativa a través de los Centros Asociados de la UNED. Delegación que, obviamente, no se ha producido, al menos de momento.

Respecto a la naturaleza y régimen jurídico de la competencia, y conscientes de que se podría haber atribuido como una competencia propia, el legislador estatal ha optado por incluirla como una nueva competencia delegada ex art. 27.3.o) LBRL. En nuestra opinión, debería haberse respetado como competencia propia, ya sea mediante su inclusión en el art. 25 LBRL o mediante una disposición adicional ${ }^{14}$. En este sentido y

${ }^{14}$ Limitándola si se considera necesario en atención a la población. Conscientes en este 
como competencia propia se ejercería con autonomía y plena responsabilidad, lo que sería fundamental en atención al importante valor añadido que aportan los municipios, en cuya voluntad inicial se encuentra el verdadero origen y razón de ser de la implantación de muchos de los Centros a día de hoy existentes y cuyo papel puede verse ahora relegado a un segundo plano, al poder convertirse los Centros en meras delegaciones sin participación activa por parte del municipio, quien, en el mejor de los casos, se convertirá en un mero gestor sin capacidad de decisión.

Sea como fuere debemos atender a la nueva naturaleza de la competencia delegada, así como a la necesidad del ejercicio efectivo de la delegación por parte del Estado, analizando los términos en que se debe producir, los plazos y su contenido.

De conformidad con los apartados 1 y 3 del art. 7 LBRL en su redacción dada por la LRSAL: «1. Las competencias de las entidades locales son propias o atribuidas por delegación [...] 3. El Estado y las Comunidades Autónomas, en el ejercicio de sus respectivas competencias, podrán delegar en las entidades locales el ejercicio de sus competencias. Las competencias delegadas se ejercen en los términos establecidos en la disposición o en el acuerdo de delegación, según corresponda, con sujeción a las reglas establecidas en el art. 27, y preverán técnicas de dirección y control de oportunidad y eficiencia».

En lo que ahora nos interesa -y más allá de los criterios establecidos para cumplir con los principios de eficacia, eficiencia, no duplicidad, estabilidad presupuestaria y sostenibilidad financiera y del órgano delegante (el Estado) — se requiere que la delegación de la competencia:

- Sea aceptada voluntariamente por el ayuntamiento (art. 27.5 LBRL).

- Por un período mínimo de cinco años.

- Vaya acompañada de la correspondiente financiación, siendo nula sin dicha dotación (art. 27.6. LBRL).

— La dirección y control corresponda a la Administración delegante.

En este sentido es destacable, en primer lugar, la importancia de la voluntariedad de la aceptación y del plazo establecido para la delegación.

caso de que nos encontramos ante un servicio que trasciende al municipio, por lo que existen algunos Centros Asociados de gran relevancia por la población a la que se dirigen. Es decir, una cosa es la población del municipio donde se implanta el servicio y otra bien distinta su alcance real. Así, por ejemplo, el centro de Calatayud no va dirigido — simplemente- a la población de referencia, sino a una amplia zona de afección en la que residen más de 800.000 personas. 
Una y otra cuestión guardan relación con la imprescindible estabilidad que toda prestación pública debe gozar, máxime si tenemos en cuenta las importantes inversiones a realizar para adaptar el servicio a las nuevas tecnologías, en lo que la UNED es referencia, pero cuyo coste es indiscutible. En segundo lugar, la financiación - hasta ahora asumida por los municipios, provincias y por la propia UNED_ correrá a cargo íntegramente del Estado. Ésta es una de las importantes consecuencias del cambio de régimen jurídico de la competencia, hasta ahora propia, con la LRSAL delegada. Y en este punto resulta esencial definir el coste del servicio, para lo cual no sólo hay que atender a lo académico (las tutorías), sino también a las aportaciones dinerarias consistentes en equipamientos, medios materiales y personales. Finalmente, respecto a la dirección y control debe quedar claro un importante límite, consistente en el necesario respeto a la autonomía universitaria derivada de la Constitución y de la LOU.

Por otro lado, pero no por ello menos relevante, debemos advertir de la importancia del plazo para hacer efectiva la delegación (tres años desde la aprobación de la LRSAL), conscientes de que ha pasado uno y de que en medio de los dos restantes se van a producir unas elecciones municipales y generales con las consecuencias (prácticas) que de ello se derivan (ex ante y ex post). Asimismo, respecto del contenido del decreto existen cuestiones significativas como las relacionadas con la apertura de nuevos Centros Asociados o la propia ampliación de los servicios académicos ya prestados de manera efectiva y cuya consecuencia será un incremento de la calidad del servicio, pero también de su coste.

\section{LAS CONSECUENCIAS DE LA LRSAL SOBRE EL RÉGIMEN JURÍDICO DE LOS CONSORCIOS Y SUS IMPLICACIONES PARA LOS CENTROS ASOCIADOS DE LA UNED}

Finalmente debe darse cuenta de la modificación introducida por la disposición final segunda LRSAL ${ }^{15}$, en virtud de la cual se recoge un nuevo régimen jurídico de los consorcios. Semejante medida es trascendental, por cuanto su actividad está vinculada a su necesaria adaptación. $\mathrm{Al}$ respecto interesa destacar el plazo, su contenido y su alcance.

15 Se modifica la Ley 30/1992, de 26 de noviembre, de Régimen Jurídico de las Administraciones Públicas y del Procedimiento Administrativo Común, para incluir una nueva disposición adicional, la vigésima, con la siguiente redacción: «Disposición adicional vigésima. Régimen jurídico de los consorcios». 
En cuanto al plazo, y a tenor de la disposición transitoria sexta LRSAL, habrá que entender que la adecuación deberá producirse con carácter previo al 31 de diciembre de 2015 respecto al régimen de adscripción en los términos previstos por la disposición final segunda LRSAL y sobre lo que volveremos en breve. Dicho lo cual, y como se deriva del inciso final de la referida disposición final, «si esa adaptación diera lugar a un cambio en el régimen jurídico aplicable al personal a su servicio o en su régimen presupuestario, contable o de control, este nuevo régimen será de aplicación a partir del 1 de enero del año siguiente».

En cuanto al contenido de la adaptación, nos interesa destacar dos cuestiones. La primera relacionada con el régimen de adscripción. La medida pretende introducir un importante elemento de control, lo que parece del todo razonable. Dicho lo cual, respecto a los Centros Asociados debemos ser conscientes de que, excluidos los que están constituidos como fundaciones (los menos), se encuentran dentro del régimen propio de los consorcios (más allá de la nomenclatura empleada, siendo la más común la de patronatos). Por tanto, el problema reside en que, a priori, el sentido común invita a que sea la UNED la Administración a la que se adscriban los centros. Y ello en base a la propia naturaleza del servicio que se presta (educativo y, en su caso, cultural). Ahora bien, en términos amplios, que habrá que precisar respecto al caso concreto, dichos consorcios están integrados por municipios, provincias, la UNED y, circunstancialmente, por Cajas de Ahorros u otras entidades públicas o privadas. Por tanto, y en atención a los criterios empleados por la LRSAL, el criterio más razonable para determinar la adscripción estaría relacionado con el primer supuesto (mayoría de votos en los órganos de gobierno). Más allá de las posibles modificaciones que dicho criterio pueda suponer en la composición de alguno de los consorcios, lo cierto es que en la situación actual (de evidente crisis económica) parece razonable pensar que ninguna de las otras entidades estarán interesadas en lograr el régimen de adscripción y ello por las consecuencias que de ello se derivan.

En tercer lugar, y en cuanto al alcance de la modificación introducida por la LRSAL, debemos hacer referencia al apartado 4 de la disposición final segunda LRSAL, en virtud del cual: «Los consorcios estarán sujetos al régimen de presupuestación, contabilidad y control de la Administración Pública a la que estén adscritos, sin perjuicio de su sujeción a lo previsto en la Ley Orgánica 2/2012, de 27 de abril, de Estabilidad Presupuestaria y Sostenibilidad Financiera. En todo caso, se llevará a cabo una auditoría de las cuentas anuales que será responsabilidad del órgano de control 
de la Administración a la que se haya adscrito el consorcio. Los consorcios deberán formar parte de los presupuestos e incluirse en la cuenta general de la Administración Pública de adscripción».

Se trata, por tanto, de una modificación razonada y razonable, pero preocupante por la singularidad de los consorcios educativos de la UNED. Primero, por su importante número. Segundo, por las consecuencias no de la responsabilidad derivada de la medida, sino del coste derivado de su ejercicio efectivo y de la necesaria inclusión en los presupuestos de la Administración Pública de adscripción, así como en atención a la necesaria asunción del personal.

Finalmente debemos ser críticos con la falta de seguridad jurídica derivada de medidas como la actual, a las que se suman otras nuevas e incluso algunas que simplemente se anuncian pero cuyo contenido se adivina. En este sentido nos estamos refiriendo a la novedosa Ley 15/2014, de 16 de septiembre, de racionalización del sector público y otras medidas de reforma administrativa ${ }^{16}$, en cuya exposición de motivos se anuncia expresamente:

«La presente Ley introduce un régimen jurídico con carácter básico, sencillo y ex novo del derecho de separación de los miembros del consorcio administrativo, y cuando ello dé lugar a su disolución se establecen las reglas por las que se regirá. Posteriormente, en la futura Ley de Régimen Jurídico de las Administraciones Públicas se incluiría un régimen integral (creación, adscripción, funcionamiento, disolución) y básico referido a los consorcios que derogaría esta regulación y lo previsto en la Ley 27/2013, de 27 de diciembre, de Racionalización y Sostenibilidad de la Administración Local. Sin embargo, contar ya con estas normas permitirá a cualquier Administración Pública poder ejercer su derecho de separación del consorcio cuando considere que sea la solución más adecuada para la sostenibilidad de las cuentas públicas y se den los requisitos legales para ello. Con este nuevo régimen se mejora la sostenibilidad y eficiencia de los consorcios y la seguridad jurídica de sus miembros».

Aspectos a los que los consorcios deberán asimismo ajustarse, conscientes de las obligaciones surgidas de la LRSAL, de la actual LRSP, de sus indiscutibles consecuencias y conocedores de que en breve surgirán nuevas, y no por ello coincidentes, obligaciones legales.

${ }_{16}$ BOE, núm. 226, de 17 de septiembre de 2014. Al respecto véase Capítulo II, Sección $2 .{ }^{a}$, «Consorcios». 


\section{CONCLUSIONES}

Llegados a este punto debemos ser conscientes de la importante encrucijada en la que se encuentran los Centros Asociados de la UNED como consecuencia de una modificación legislativa de carácter sectorial, pero con implicaciones directas en un servicio cuya calidad, eficacia y eficiencia no pueden ser objeto de discusión. Máxime cuando nos encontramos ante una realidad caracterizada por vertebrar el país en términos educativos, sociales y culturales, y que, cumpliendo con los postulados que persigue la propia reforma articulada por la LRSAL, puede tener como consecuencia final su desarticulación.

Sirva este trabajo para requerir de la autoridad competente, el Estado, un ejercicio de responsabilidad en el mantenimiento de un servicio de educación superior, de él dependiente, y con una estructura organizativa estable y con presencia en todo el territorio nacional.

Finalmente no podemos terminar el presente análisis sin hacer una última reflexión con la que pretendemos poner de manifiesto la inconsistencia de las consecuencias de haber eliminado — sin más reflexión- la competencia municipal en materia de educación. Nos estamos refiriendo a que cabe la posibilidad de que los Centros Asociados pierdan su sentido en términos educativos, pero pudieran mantenerse en términos culturales. Y es que da la casualidad de que con los años, y como consecuencia de su estabilidad y fuerte implantación, la UNED ha ido avanzando en la mejora de los mismos y en la prestación de otros servicios más cercanos a la competencia en materia de cultura, siempre conscientes de que la base sólida de su actividad (conceptual y material) sea $-\mathrm{y}$ es- la educativa. Nos estamos refiriendo a servicios como la UNED senior, el Centro Universitario de Idiomas a Distancia (CUID), la formación permanente o la Extensión Universitaria. Estando su papel principal estrecha y directamente vinculado con el ámbito académico, se podría producir la paradoja de que dicho servicio no pudiera ser objeto de prestación por ser estrictamente educativo, dejando a salvo el resto de servicios educativo-culturales o sencillamente culturales que dependen de la misma y cuyo éxito es indiscutible.

Reflexión ésta que nos lleva a realizar una propuesta de lege ferenda consistente en apelar no ya al gobierno a los efectos de cumplir con las exigencias derivadas de la LOU y ahora de la propia LRSAL, sino al legislador estatal, quien también debe asumir su papel y quien podría aprobar una ley para la UNED con la que, desde el máximo respeto a la autono- 
mía universitaria y al ámbito que pueda corresponder al ejecutivo para desarrollar sus contenidos, terminara por resolver los numerosos problemas a los que se enfrenta la institución educativa de referencia originados por los constantes vaivenes no ya de la normativa propia (la educativa), sino de cambios producidos en ámbitos sectoriales (como es el caso de la LRSAL) y cuyos efectos - en muchos de los casos involuntarios- son del todo discutibles. La ley a la que hacemos referencia supondría otorgar la estabilidad necesaria a una estructura organizativa ya existente y asentada, resolviendo los problemas a los que se enfrenta la UNED al tratarse de una realidad singular que se ve afectada por los cambios normativos que en ningún caso atienden a la misma ni a sus verdaderas necesidades. En cuanto a su contenido debería regular: el régimen jurídico de los Centros; la definición de la función tutorial; la definición de la acción exterior de la UNED y su coordinación con el Instituto Cervantes, y el régimen de financiación. Cuatro puntos clave que debería, cuanto menos, recoger una ley ordinaria aprobada en Cortes Generales para la UNED. Ésa era la idea que parecía subrayar la redacción original de la LRU, mantenida posteriormente en la disposición adicional primera de la LOU, en lo que se refiere a las competencias de las Cortes Generales sobre la UNED (idénticas a las establecidas por la LOU a las asambleas legislativas de las Comunidades Autónomas sobre las universidades de su territorio). 